\title{
Title:
}

\section{Hiatal hernia and Cameron ulcer: an overlooked association in pediatric patients}

\section{Authors:}

Helena Moreira Silva, Ricardo Küttner-Magalhães, Rosa Lima

DOI: $10.17235 /$ reed.2021.8000/2021

Link: PubMed (Epub ahead of print)

Please cite this article as:

Moreira Silva Helena, Küttner-Magalhães Ricardo, Lima Rosa. Hiatal hernia and Cameron ulcer: an overlooked association in pediatric patients . Rev Esp Enferm Dig 2021. doi: 10.17235/reed.2021.8000/2021.

This is a PDF file of an unedited manuscript that has been accepted for publication. As a service to our customers we are providing this early version of the manuscript. The manuscript will undergo copyediting, typesetting, and review of the resulting proof before it is published in its final form. Please note that during the production process errors may be discovered which could affect the content, and all legal disclaimers that apply to the journal pertain. 
CC 8000

\section{Hiatal hernia and Cameron ulcer: an overlooked association in pediatric patients}

Helena Moreira Silva ${ }^{1}$, Ricardo Küttner-Magalhães ${ }^{2}$, Rosa Lima ${ }^{1}$

${ }^{1}$ Pediatric Gastroenterology Unit. Centro Materno Infantil do Norte and ${ }^{2}$ Gastroenterology Department. Hospital Santo António. Centro Hospitalar Universitário do Porto. Porto, Portugal

Correspondence: Helena Moreira Silva

e-mail: hel.m.silva@hotmail.com

Keywords: Cameron ulcer. Hiatal hernia. Iron deficiency anemia.

Conflicts of interest: the authors declare no conflicts of interest.

Dear Editor,

A ten-year-old boy presented with a two-year history of iron deficiency anemia (IDA) and occasional vomiting. His medical history included cerebral palsy and chronic pulmonary disease under mechanical cough assistance and nocturnal non-invasive ventilation. He had already been treated with proton-pump inhibitors (omeprazole 20 $\mathrm{mg}$ per day) and iron supplements because of a previous diagnosis of gastroesophageal reflux disease (GERD). Esophagogastroduodenoscopy revealed a sliding hiatal hernia and an 8-mm ulcer with a clean base, involving the diaphragmatic hiatus at the lesser curvature level, which was consistent with a Cameron ulcer. During the examination, it was possible to see the proximal stomach moving up and down through the diaphragmatic hiatus, with active oozing bleeding from the ulcer. A laparoscopic herniorrhaphy and fundoplication were performed. After 6-month followup, vomiting and IDA had totally resolved. Unfortunately, the patient died one year 
later because of acute respiratory insufficiency.

Cameron lesions and hiatal hernias are uncommonly reported in adults evaluated for gastrointestinal bleeding, and the prevalence ranges from $0.6 \%$ to $5 \%$ (1). However, there are only a few case reports in children. Besides a poorly understood pathogenesis, it can be attributed to mechanical trauma of the hiatal hernia caused by respiration-related diaphragmatic movements and acid injury (2-4). We hypothesize that in our patient, the pressure difference between the abdomen and thorax generated by ventilatory support not only aggravated GERD but also contributed to an exacerbation of the hernia's sliding movement and distress of the mucosa, ultimately leading to ulceration. Pseudobulbar palsy with impaired airway clearance and lung function were the main causes of his unfavorable outcome.

Although a rare occurrence and cause of acute or chronic gastrointestinal bleeding (5), a hiatal hernia in a child with IDA should raise the suspicion of Cameron lesions. Firstline treatment is long-term acid suppression and iron supplements. Surgery is recommended for patients whose lesions are refractory to medical treatment.

\section{REFERENCES}

1. Camus M, Jensen DM, Ohning GV, et al. Severe upper gastrointestinal hemorrhage from linear gastric ulcers in large hiatal hernias: a large prospective case series of Cameron ulcers. Endoscopy 2013;45(5):397-400. DOI: $10.1055 / s-0032-1326294$

2. Cameron AJ, Higgins JA. Linear gastric erosion. A lesion associated with large diaphragmatic hernia and chronic blood loss anemia. Gastroenterology 1986;91:338-42.

3. Chun CL, Conti CA, Triadafilopoulos G. Cameron ulcers: you will find only what you seek. Dig Dis Sci 2011;56:3450-52. DOI: 10.1007/s10620-011-1803-y

4. Maganty K, Smith RL. Cameron Lesions: Unusual Cause of Gastrointestinal Bleeding and Anemia. Digestion 2008;77(3-4):214-7. DOI: 10.1159/000144281

5. Kimer N, Schmidt PN, Krag A. Cameron lesions: an often overlooked cause of iron deficiency anaemia in patients with large hiatal hernias. BMJ Case Rep 
2010;28;2010. DOI: 10.1136/bcr.06.2010.3129 